\title{
Pengaruh Kondisi Lingkungan Terhadap Bentuk Bangunan Arsitektur
}

\author{
Fitry Aditya Fananiar ${ }^{1 *}$, Jullinar Dwi Pangesti ${ }^{1}$, Heru Prasetiyo ${ }^{2}$ \\ ${ }^{1}$ Mahasiswa, Arsitektur, Fakultas Arsitektur dan Desain, Universitas Pembangunan Nasional 'Veteran' Jawa Timur \\ ${ }^{2}$ Dosen, Arsitektur, Fakultas Arsitektur dan Desain, Universitas Pembangunan Nasional ‘Veteran' Jawa Timur \\ *e-mail: fitryadityaf@gmail.com; Telp. +62 89537146868
}

\begin{abstract}
Abstrak:
Bangunan arsitektur memiliki fungsi dalam menciptakan kebutuhan ruang dari penggunanya (manusia). Dalam perwujudannya tidak lepas dari pengaruh kondisi fisik lingkungan yang membentuk iklim mikro di sekitarnya. Bentuk bangunan di Indonesia yang beriklim tropis lembab jika diamati dengan bentuk bangunan di daerah Eropa akan berbeda karena perbedaan iklim dari kedua lokasi. Tetapi, kebanyakan orang kurang memperhatikan hal tersebut. Penelitian ini akan mengkaji tentang seberapa besar pengaruh kondisi fisik lingkungan terhadap bentukan bangunan arsitektur. Metode yang digunakan adalah metode korelasi dengan membandingkan bentuk bangunan khususnya perumahan di daerah Surabaya Timur dengan di Surabaya Barat, yang mana kedua lokasi ini memiliki karakteristik fisik lingkungan yang berbeda. Pengambilan data dilakukan dengan observasi langsung serta dari beberapa sumber literatur dan internet. Hasil penelitian menunjukkan bahwa pengaruh lingkungan dapat berdampak terhadap bentuk atau ide dalam suatu bangunan arsitektur walaupun dalam hal sekecil apapun.
\end{abstract}

Kata Kunci: bentuk; bangunan; arsitektur

\section{Latar Belakang}

Bangunan arsitektur memiliki fungsi dalam menciptakan kebutuhan ruang untuk mewadahi aktifitas penggunanya (manusia). Agar dapat melakukan aktifitas degan baik, maka faktor kenyamanan menjadi penting. Salah satu hal yang berkaitan dengan kenyamanan adalah kondisi iklim yang sangat dipengaruhi oleh kondisi fisik suatu wilayah. Maka untuk mewujudkan kenyamanan didalam bangunan seorang arsitek harus bisa memahami keadaan lingkungan sekitar tapak serta menganalisisnya sabagai dasar pengambilan keputusan didalam mendesain sebuah bangunan.

Rumah merupakan salah satu jenis bangunan yang paling lama dan sering ditempati, karena dari tempat ini sesorang memulai dan mengakhiri aktivitas hariannya. Oleh karena itu pertimbangan kenyamanan bangunan sangatlah penting. Selain memperhatikan iklim, sebuah karya arsitektur harus juga dituntut mampu menonjolkan sisi estetika melalui pola bentukan, material, dan lainnya. Hal ini juga termasuk perumahan, dimana selain nyaman sebuah perumahan yang bagus juga akan memberikan nilai prestis tersendiri bagi penghuninya.

Kota Surabaya memiliki banyak kawasan perumahan yang dikembangkan oleh developer. Umumnya lokasi perumahan berada di pinggiran kota. Salah satu kawasan pemukiman yang cukup bagus adalah perumahan Pakuwon City di Surabaya Timur dan perumahan Grand Pakuwon di Surabaya Barat. Kedua perumahan tersebut dikembangkan oleh perusahaan yang sama, yaitu Pakuwon Group yang merupakan anak perusahaan dari PT. Pakuwon Jati. Pakuwon Group memiliki misi ingin membangun pengembangan Township yakni suatu kawasan permukiman yang maju, tetapi ukurannya terlalu kecil untuk disebut kota. Meskipun berada dalam satu kota, namun kedua lokasi perumahan tersebut memiliki karakteristik fisik lingkungan yang berbeda sehingga sedikit banyak akan berpengaruh terhadap kondisi iklim di daerah tersebut.

Pada penelitian ini, mencoba menggali lebih jauh dan mengenal bagaimana pengaruh lingkungan terhadap perwujudan bangunan, apakah konservasi fasad, material bangunan pada daerah Surabaya Timur dan Surabaya 
Barat, serta bagiamana perwujudan bentuk bangunan jika berangkat dari konsep yang sama, tetapi memiliki karakteristik masing-masing lokasi yang berbeda.

\subsection{Rumusan Masalah}

Berdasarkan latar belakang di atas, maka permasalahan yang di tinjau antara lain:

1) Seberapa besar peran lingkungan mempengaruhi bentuk hasil rancangan?

2) Bagaimana rancangan bangunan yang menghasilkan kenyamanan bagi pengguna ?

3) Apakah dengan konsep yang sama, tetapi lokasi berbeda akan menghasilkan bentuk yang berbeda ?

\subsection{Tujuan Penelitian}

Maksud dan tujuan dalam penelitian ini adalah sebagai berikut:

1) Untuk mengetahui seberapa besar faktor lingkungan terhadap rancangan bentuk bangunan.

2) Untuk mengetahui solusi yang bisa diterapkan dalam merancang bentuk bangunan dengan memperhatikan faktor lingkungan.

3) Mengetahui perwujudan bentuk bangunan dengan konsep yang sama, tetapi di lokasi yang berbeda.

\section{Metode Penelitian}

Untuk menyelidiki pengaruh lingkungan fisik dengan bentuk bangunan, maka penelitian ini menggunakan metode penelitian korelasi, dimana pengumpulan data primer dilakukan secara observasi langsung serta ditambah data sekunder dari sumber literatur maupun internet. Adapun proses analisis data meliputi, analisis lingkungan di masing-masing lokasi serta analisa sirkulasi maupun pergerakan tata ruang dari suatu pemukiman. Analisis data yang telah dikumpulkan bertujuan untuk menentukan apakah ada hubungan antara bentuk bangunan dengan kondisi lingkungan tapak. Analisis ini bertujuan untuk membandingkan bentuk perumahan di daerah Surabaya Timur dan Surabaya Barat. Dan mengetahui solusi bentuk dari penyelesaian yang diterapakan sesuai kondisi lingkungan tersebut.

\section{Hasil dan Pembahasan}

\subsection{Kondisi Fisik Lingkungan Surabaya Timur dan Surabaya Barat}

Surabaya merupakan ibukota Provinsi Jawa Timur yang posisinya berada di $07^{\circ} 9^{\prime}$ hingga $07^{\circ} 21^{\prime}$ Lintang Selatan dan $112^{\circ} 36^{\prime}$ hingga $112^{\circ} 54^{\prime}$ Bujur Timur. Surabaya yang merupakan bagian dari Indonesia memiliki iklim tropis lembab. Wilayah di Surabaya terbagi atas kawasan Pusat, Barat, Timur, Utara, dan Selatan. Surabaya memiliki luas $333,063 \mathrm{~km}^{2}$ dengan penduduk 2.909.257 jiwa (2015) yang menjadikan Surabaya kota yang padat penduduk. Dalam penelitian ini, kami membandingkan bentuk bangunan Surabaya Timur dan Surabaya Barat.

\subsubsection{Kondisi Lingkungan di Surabaya Timur}

Wilayah Surabaya Timur merupakan daerah pesisir atau dikatakan wilayah ruang laut. Pantai Kenjeran yang berada di wilayah Surabaya Timur membuat suhu pada daerah ini panas dan memiliki hembusan angin yang lebih kencang jika dibandingkan dengan wilayah Surabaya lainnya. Secara topografi, dataran di Surabaya Timur memiliki ketinggian antara 3 sampai 6 meter di atas permukaan laut dengan kemirinngan kurang dari 3\% sehingga bisa dikatakan dataran rendah yang cukup datar.

\subsubsection{Kondisi Lingkungan di Surabaya Barat}

Wilayah Surabaya Barat merupakan area perbukitan landai dengan ketinggian 25-50 meter di atas permukaan laut dan memiliki kemiringan 5\% hingga 15\%. Maka, tidak heran jika di wilayah Surabaya Barat memiliki kondisi tanah atau jalan yang lebih berkontur jika dibandingkan dengan wilayah Surabaya lainnya. 


\subsection{Analisis Tapak}

Pemilihan lokasi tapak merupakan salah satu hal penting yang dipertimbagkan oleh developer dalam mengembangkan suatu kawasan, termasuk perumahan. Pakuwon Group adalah perusahaan real estate yang melopori konsep superblock di Indonesia. Pengembangan terintegrasi skala besar dari pusat belanjaan ritel, perkantoran, kondominium, apartemen, dan hotel. Di Surabaya Perusahaan real estate Pakuwon Group terdiri dari tiga perusahaan, yaitu Pakuwon Indah, Pakuwon City, dan Grand Pakuwon. Dalam penelitian ini akan menganalisa lebih dalam terhadap Pakuwon City yang mewakili Surabaya Timur dan Grand Pakuwon yang mewakili Surabaya Barat.

\subsubsection{Pakuwon City}

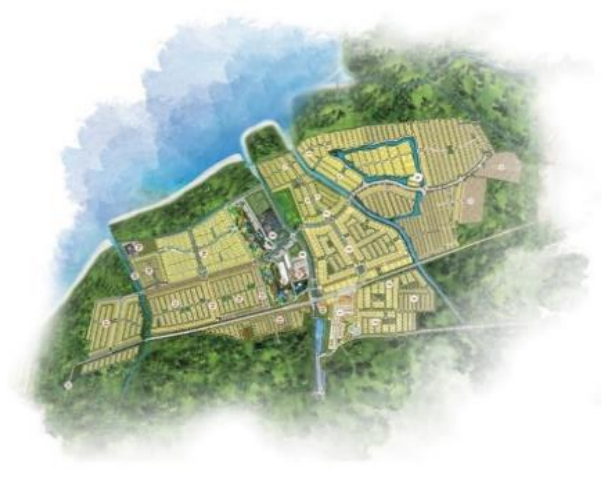

Gambar 1. Master Plan Pakuwon City

(Sumber: Website Pakuwon Group)

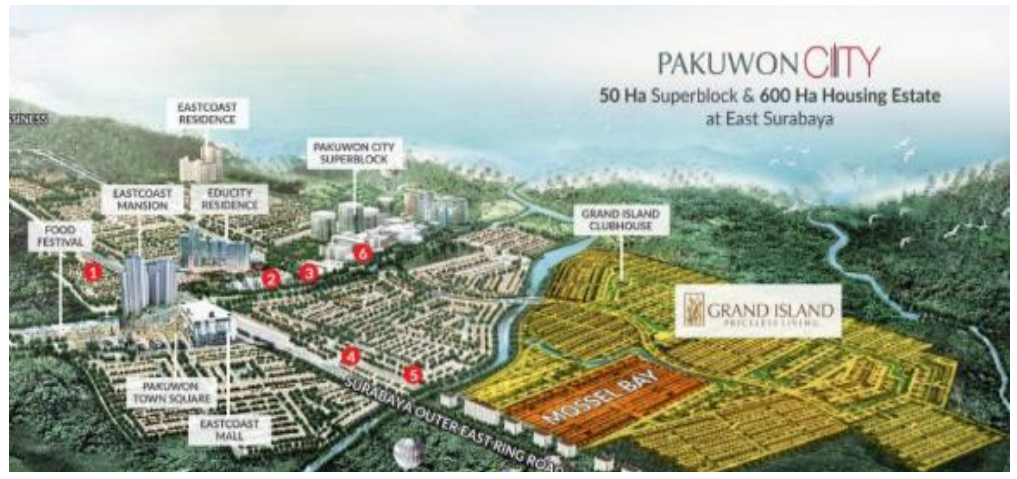

Gambar 2. Block Plan Pakuwon City

(Sumber: Website Pakuwon Group)

Lokasi tapak pertama adalah perumahan elit Pakuwon City yang berada di Surabaya bagian timur. Dengan luas lahan 600 hektar. Lokasi ini berdekatan dengan area pesisir pantai (Pantai Kenjeran). Konsep yang ingin ditampilkan pada Pakuwon City adalah 'Kota Mandiri', yaitu suatu kawasan yang dirancang dan dikembangkan tidak hanya sebagai hunian semata saja, tetapi juga dilengkapi dengan fasilitas rekreasi, pendidikan, pusat perbelanjaan, dan kuliner. Jika melihat dari Master Plan pengembangan kawasan ini memiliki bentuk tatanan rumah pada tiap blok yang berbeda yakni berpola linier dan juga berpola grid.

\section{Akses Sirkulasi}

Untuk akses sirkulasi menuju Pakuwon City dapat diakses dari dua arah, yang pertama dari Jl. Kertajaya sampai kawasan kampus ITS dan kedua dari Kenjeran yang langsung masuk melewati EORR (East Outer Ring Road). Jalur pertama tersebut menghubungkan Pakuwon City ke MERR (Middle East Ring Road) atau Jalan Dr. Ir. H. Soekarno sehingga dari sisi aksebilitas lokasi tapak Pakuwon City sangat strategis.

\section{A. Cluster Mosselbay Tipe Maica di Pakuwon City}

Pakuwon City memiliki kawasan perumahan yang cukup luas dan dibagi menjadi beberapa cluster. Pada penelitian ini akan menganalisis salah satu cluster yakni cluster Mosselbay tipe Maica dengan Luas Tanah (LT)/ Luas Bangunan (LB) 144/ 179 m² dan memiliki dua lantai. Cluster ini menerapkan konsep 'Luxury and Modern', yaitu perpaduan antara hunian arsitektur modern dengan lingkungan hijau untuk memberikan kenyamanan hidup. Untuk akses sirkulasi di Cluster Mosselbay tipe Maica memiliki lebar jalan 7 meter, dengan sirkulasi kendaraan dari dua arah. 


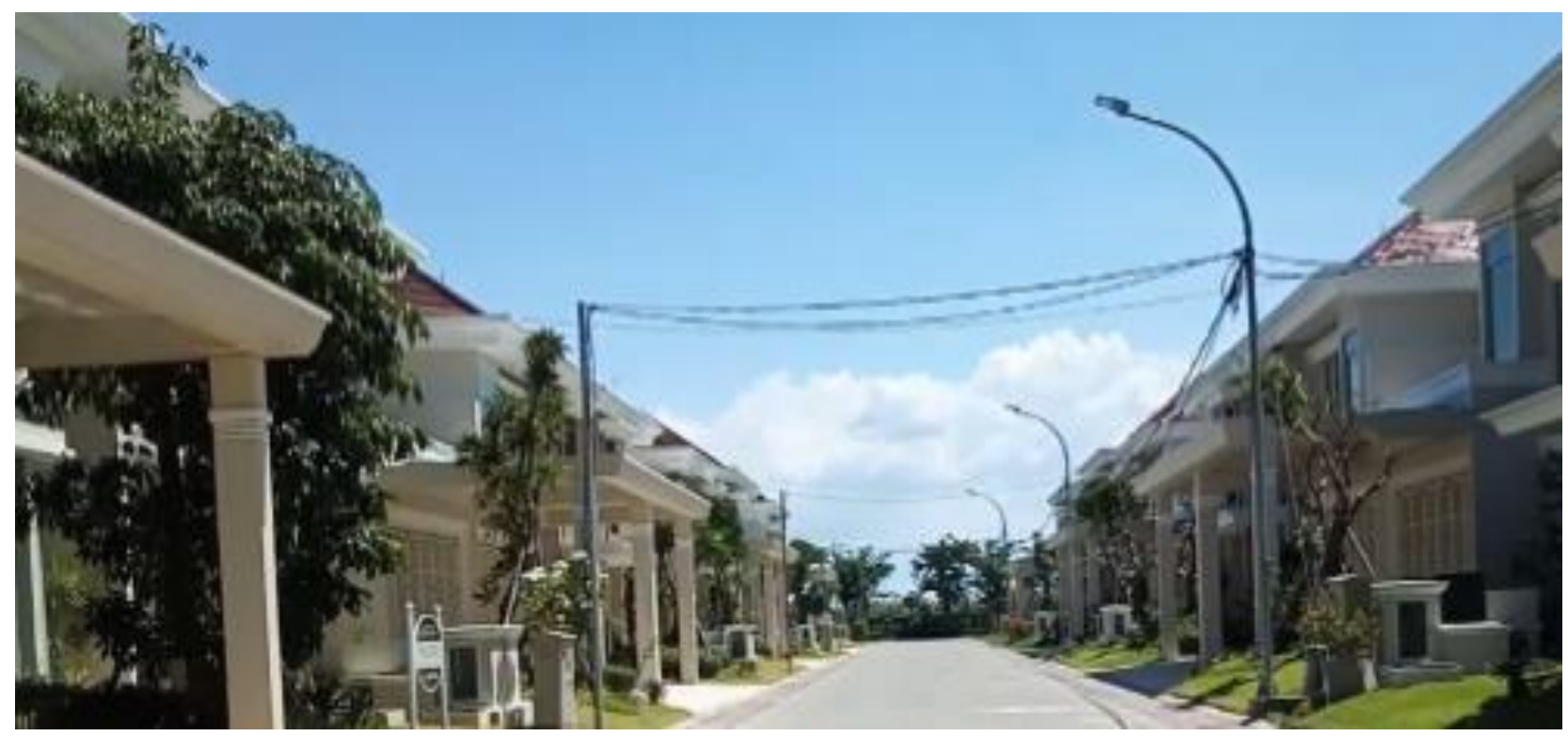

Gambar 3. Lokasi Tapak

(Sumber: Google Maps)

\section{Bentuk Denah}

Bentukan dasar denah adalah persegi panjang. Dibagian depan maupun belakang terdapat taman, dan bukaan jendela dan pintu, sehingga memerikan akses sirkulasi penghawaan (penerapan cross ventilation/ ventilasi silang). Pembagian ruang pada rumah tipe Maica antara lain:

1. 4 Kamar Tidur

2. 4 Kamar Mandi

3. 1 Kamar Tidur + 1 Kamar Mandi (untuk ART)

4. Ruang Tamur

5. Ruang Makan

6. Carport (untuk 2 Mobil)

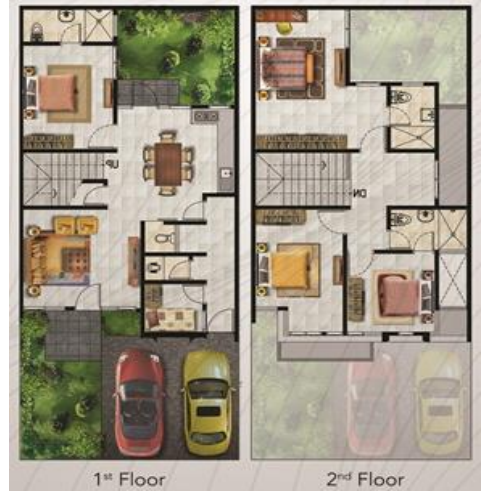

Gambar 4. Denah Tipe Maica

Sumber: Website Pakuwon Group

\section{Bentuk Fasad}

Bentuk atap yang digunakan adalah jenis atap perisai. Karena memiliki konsep ingin memadukan antara arsitektur modern dengan lingkungan hijau, maka bentuk fasad tidak terlalu banyak ornamen serta finishing warna terang dengan perpaduan material Granit yang bercorak batu alam sehingga memberikan kesan natural.

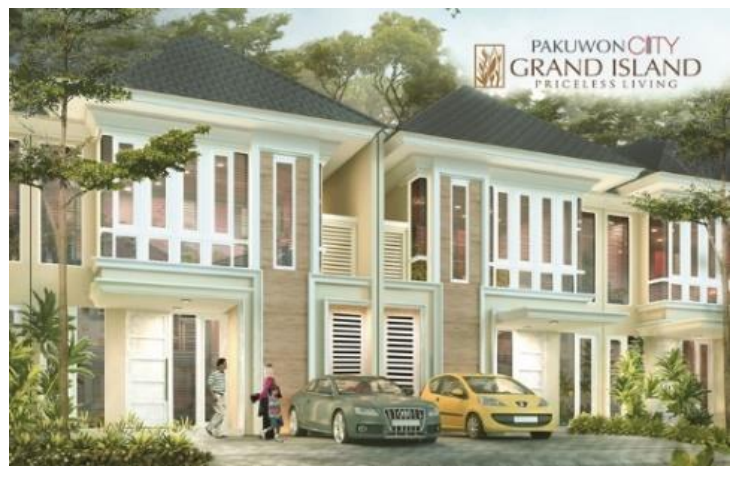

Gambar 5. Rumah Tipe Maica

Sumber: Website Pakuwon Group 


\subsubsection{Grand Pakuwon}

Lokasi tapak kedua adalah perumahan elit Grand Pakuwon yang berada di Surabaya bagian barat. Dengan luasan area tapak 400 hektar. Konsep yang ditampilkan pada Grand Pakuwon tidak jauh beda dengan Pakuwon City karena keduanya berada disatu perusahaan real estate yang sama. Namun, pada bagian tatan pola Grand Pakuwon memiliki pola yang sama antar tiap blok, yaitu pola linier.

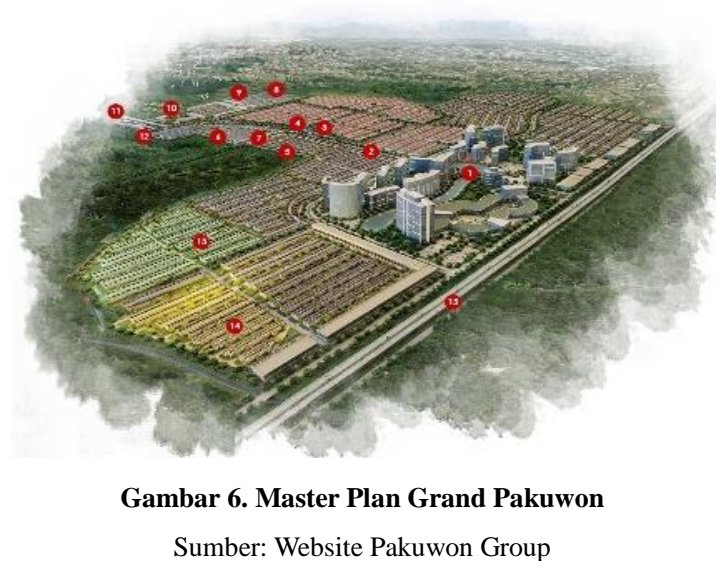

\section{Akses Sirkulasi}

Untuk akses sirkulasi menuju Grand Pakuwon ada tiga, yaitu dari Tol Margomulyo, Jalan Margomulyo Indah, dan Jalan Banjar Sugihan. Lebar jalan utama 30 meter dengan melintasi kota dan jalan tambahan sekitar 18 hingga 20 meter yang mengarah pada setiap cluster pembangunan.

\section{A. Cluster North Victoria Tipe Hampton di Grand Pakuwon}

Kawasan perumahan Grand Pakuwon juga cukup luas, dalam penelitian ini akan mengkaji area perumahan cluster North Victoria tipe Hampton dengan luas tanah (LT)/ luas bangunan (LB) 144/ $158 \mathrm{~m}^{2}$ dan memiliki 2 lantai. North Victoria merupakan salah satu cluster premium dan berlokasi cukup strategis di jantung kota mandiri Grand Pakuwon yang menerapkan suasana Australia ke Surabaya.

\section{Bentuk Denah}

Bentukan dasar denah adalah persegi panjang. Jika kita bandingkan bentuk denah Cluster North Victoria dengan Tipe Maica maka tidak jauh berbeda. Seperti dibagian depan maupun belakang terdapat taman, dan bukaan jendela dan pintu untuk penerapan cross ventilation /ventilasi silang. Adapun pembagian ruang pada tipe Hampton antara lain:

1. 3 Kamar Tidur

2. 3 Kamar Mandi

3. 1 Kamar Tidur + 1 Kamar Mandi (Untuk ART)

4. Ruang Tamu

5. Ruang Makan

6. Carport (Untuk 2 Mobil)

\section{Bentuk Fasad}

Untuk bentuk atap sama dengan tipe Maica, yaitu menggunakan atap jenis perisai. Namun, dalam bukaan jendela memiliki ukuran yang lebih lebar jika dibandingkan dengan tipe Maica.

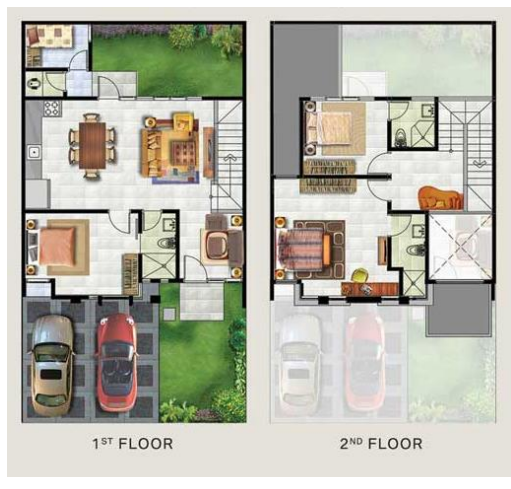

Gambar 7. Denah Tipe Hampton

Sumber: Website Pakuwon Group

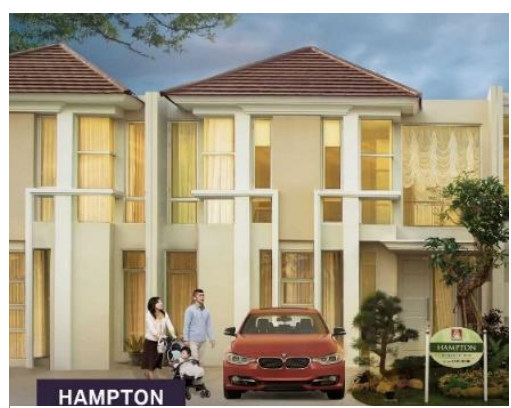

Gambar 8. Rumah Tipe Hampton

Sumber: Website Pakuwon Group 


\section{B. Cluster Brisbane Tipe Corbey di Grand Pakuwon}

Brisbone merupakan cluster terbaru bagian di Grand Pakuwon. Cluster Brisbane tipe Corbey dengan luas tanah (LT)/luas bangunan (LB) 144/158 $\mathrm{m}^{2}$ dan memiliki 2 lantai.

\section{Bentuk Denah}

Pada cluster Brisbane tipe Corbey memiliki bentuk sama dengan sebelumnya. Meskipun Brisbane termasuk cluster terbaru tetapi tetap mengikuti cluster sebelumnya. Dan terdapat taman pada bagian depan dan belakang bangunan. Ruang yang terdapat pada tipe Corbey sebagai berikut :

1. 3 Kamar Tidur

2. 3 Kamar Mandi

3. 1 Kamar Tidur + Kamar Mandi (Untuk ART)

4. Ruang Tamu

5. Ruang Keluarga

6. Dapur

7. Ruang Makan

8. Taman

9. Carport (Untuk 2 Mobil)
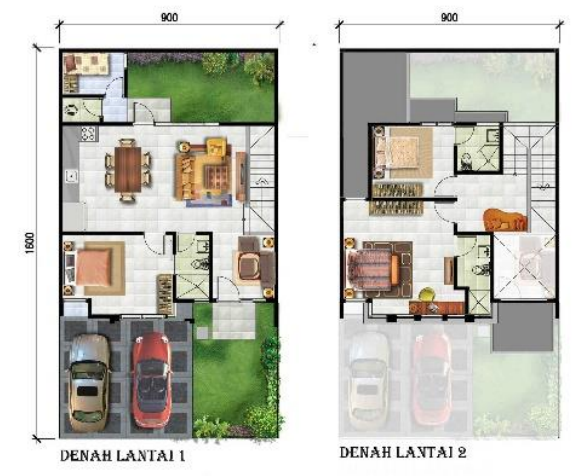

Gambar 9. Denah Tipe Corbey

Sumber : Website Pakuwon Group

\section{Bentuk Fasad}

Pada tipe Corbey memiliki bentuk atap perisai yang sama dengan cluster sebelumnya. Tetapi, pada tipe ini memiliki banyak bukaan. Dan menggunakan material kaca yang lebih dominan pada bentukan fasadnya.

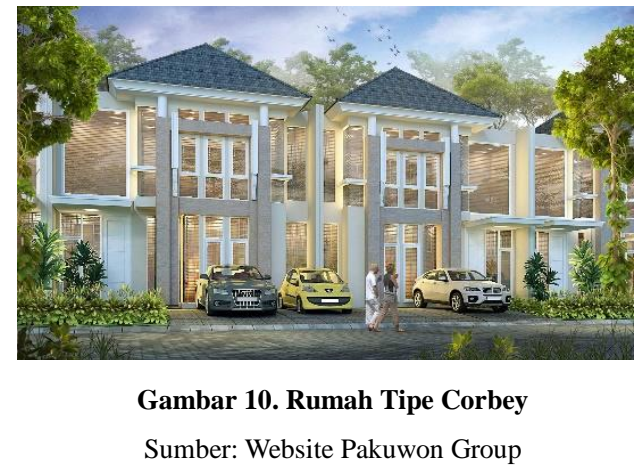

\subsection{Kebutuhan Dasar Manusia}

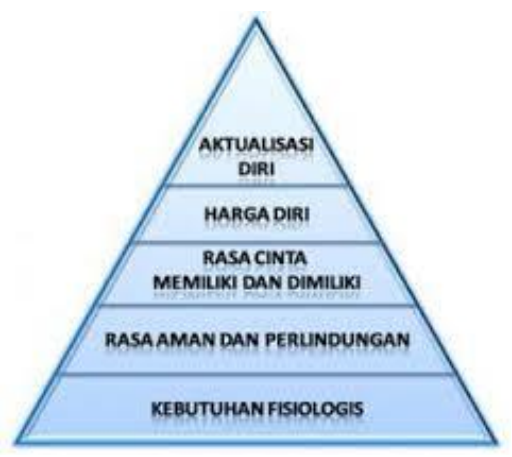

Gambar 8. Piramida Kebutuhan

Menurut Abraham Maslow

(Sumber : http://sahabat-

rianti.blogspot.com/2014/05/makalah-

kebutuhan-dasar-manusia.html)
Kebutuhan dasar manusia merupakan unsur-unsur yang diperlukan oleh manusia dalam mempertahankan keseimbangan fisiologi maupun psikologi. Hal ini bertujuan untuk mempertahankan kesehatan dan kehidupan manusia. Seorang psikolog bernama Abraham Maslow mengemukakan teori hirarki kebutuhan manusia dengan tingkatan mulai dari yang paling rendah sampai paling tinggi yang disebut dengan piramida kebutuhan dasar. Teori ini terdiri dari 5 macam kebutuhan dasar, yaitu kebutuhan fisiologi (physiological needs), kebutuhan rasa aman dan perlindungan (safety and security needs), kebutuhan rasa kasih sayang dan rasa memiliki (love and belonging needs), kebutuhan akan harga diri (esteem needs), dan kebutuhan akan aktualisasi diri (self-actualization).

Salah satu kebutuhan manusia, yaitu rasa aman dan perlindungan dapat diwujudkan dalam bentuk ruang atau tempat tinggal. Kebutuhan ini masuk dalam kategori kebutuhan akan perlindungan, kemantapan, kebebasan dari rasa takut, cemas dan kekalutan. 


\subsection{Bentuk Ruang dalam Memenuhi Aspek Kebutuhan Manusia}

Pendekatan perilaku dapat ditelusuri dari hubungan timbal balik antara ruang dan pengguna yang memfungsikannya. Selain itu latar belakang daerah yang berbeda juga perlu diperhatikan dalam melihat peraliku manusia dalam memanfaatkan ruang. Dalam pendekatan ini akan melihat aspek norma, psikologi, lingkungan, kultur, dan masyarakat yang berbeda akan menghasilkan konsep dan wujud yang berbeda. Adapun penerapan perancangan dengan pendekatan perilaku khususnya pada kawasan pemukiman dapat dilakukan melalui (Laurens, J.M, 2006):

a. Pengawasan secara alamiah (surveillance), untuk meningkatkan keleluasaan pengawasaan terhadap propertinya dan memudahkan melihat keberadaan orang asing disekitar propertinya.

b. Memperkuat batas teritorial, untuk memperjelas kepemilikan ruang yang membuat orang yang tidak dikehendaki tidak tertarik masuk ke dalamnya. Desain secara fisik dapat menciptakan atau memperbesar pengaruh sebagai ekspresi kepemilikan dan kebanggaan, sehingga dapat menciptakan kendali atas wilayahnya.

c. Pengawasan aksesibilitas, bertujuan untuk mengurangi peluang terjadinya tindak kriminal dengan mengontrol dan mengurangi akses pada sasaran potensial, dengan menekankan pembagian zona yang jelas mengenai rute mana yang bersifat publik, dan rute mana yang bersifat pribadi

d. Sistem penjagaan, bertujuan untuk mencegah akses terhadap ruang-ruang yang paling pribadi dalam suatu lingkungan.

e. Pendukung aktivitas, bertujuan untuk menempatkan aktivitas agar pelakunya menjadi bagian dari pengawasan alami.

f. Pemeliharaan, jika dilakukan secara rutin dan teratur akan menjamin kejelasan teritorial.

Komponen tersebut di atas digunakan untuk mengevaluasi kondisi fisik suatu lingkungan pemukiman kota. Saat ini pendekatan yang dipakai untuk menciptakan rasa aman di ruang kota adalah dengan Pencegahan Kejahatan melalui Perancangan Lingkungan (Crime Prevention Through Environmental Design - CPTED). Pendekatan ini dipakai untuk menciptakan rasa aman yang secara otomatis berlaku pula untuk menciptakan citra/kesan aman suatu kawasan. Pada kedua lokasi studi system pengamanan mennggunakan pendekatan dengan memperkuat batas territorial berupa cluster yang dibatasi oleh bangunan dari cluster lain serta pendekatan pengawasan aksesibilitas dan system penjagaan yakni keberadaan pos jaga untuk mengecek setiap kendaraan yang keluar masuk ke dalam cluster dengan one gate system. Dengan system ini dapat memaksimalkan segi keamanan lingkungan sehingga penghuni merasa aman dan nyaman.

\section{Kesimpulan}

Dari perbandingan desain objek tersebut dapat disimpulkan bahwa:

a) Jika dilihat dari denah, tidak ada faktor perubahan secara signifikan antara tipe satu dengan lainnya. Namun, jika kita memperhatikan dari fasad bangunan untuk jumlah serta ukuran bukaan (jendela) daerah Pakuwon City lebih kecil dan tidak sebanyak dengan daerah Grand Pakuwon. Hal ini karena faktor angin yang lebih kencang pada wilayah Surabaya Timur. Maka, ukuran bukaan lebih kecil untuk memperhatikan kenyamanan.

b) Pakuwon City dan Grand Pakuwon dari perusahaan real estat yang sama, yaitu Pakuwon Group. Tentu mereka memiliki konsep yang sama, tetapi antara cluster satu dengan yang lain memiliki bentukan fasad yang berbedabeda. Walau berbeda kesan atau konsep yang dicapai tidak hilang. Jadi, walau memiliki konsep sama bentuk fasad tidak harus sama.

c) Kedua perumahan tersebut dari segi bentuk denah maupun tatanan clusternya sudah memperhatikan dari segi keamanan bagi penghuni (Salah satu kebutuhan manusia yang perlu dipenuhi). Karena dilengkapi dengan pos satpam, dan akses masuk maupun keluar terbatas (private). 


\section{Ucapan Terima Kasih}

Pertama-tama ucapan terima kasih kepada Tuhan Yang Maha Esa karena bisa diberi kesempatan dalam menyelesaikan jurnal ini. Terima kasih juga kepada dosen UPN "Veteran" Jawa Timur yang membantu dalam merevisi jurnal ini.

\section{Daftar Pustaka}

Achmad, F.H... (2014). Ruang Terbuka sebagai Pendukung Arsitektur Pertahanan. https://onesearch.id/Record/IOS2763.6858

Laurens, J, M. (2006). Pendekatan Perilaku Lingkungan dalam Perancangan Pemukiman Kota. Dimensi. Vol 34, No.1

http://dimensi.petra.ac.id/index.php/ars/article/view/16453/16445

Sakti, dan Asri, D. (2018). Penerapan Pendekatan Rancang Active Design pada Perancangan Hunian Vertikal, http://ejurnal.its.ac.id/index.php/sains_seni/article/view/33674 